\title{
Modelling height and diameter growth of dominant cork oak trees in Spain
}

\author{
Mariola SÁNCHEZ-GONZÁLEZ ${ }^{\mathrm{a} *}$, Margarida TOMÉb ${ }^{\text {, Gregorio MONTERO }}{ }^{\mathrm{a}}$ \\ a Centro de Investigación Forestal CIFOR-INIA, Ctra. De La Coruña, km 7,5, 28040 Madrid, Spain \\ b Departament of Forestry, Instituto Superior de Agronomia, Universidade Técnica de Lisboa, Tapada de Ajuda, 1349-017 Lisbon, Portugal
}

(Received 15 November 2004; accepted 3 March 2005)

\begin{abstract}
A plan for sustainable management is urgently required for cork oak forests. This objective is only attainable through growth models that allow us to predict the medium and long term consequences of different silvicultural treatments. In this study, we have developed height and diameter growth models for dominant cork oak trees using stem analysis data from two of the main cork producing areas in Spain. Difference forms of the Lundqvist-Korf, McDill-Amateis and Richards growth functions were tested and fitted using the generalized least squares regression method. The parameters of the equations were linked to stand characteristics in order to improve the models. The difference form of the McDill-Amateis equation was selected for height growth, while the difference form of the Richards equation with $n$ as the free parameter was selected for diameter growth. These models increase our knowledge of the growth of this species and therefore will enable us to improve management planning in cork oak forests.
\end{abstract}

growth models / Quercus suber / site index / dominant trees / sustainability

Résumé - Modèles de croissance en hauteur et en diamètre pour des chênes-lièges dominants en Espagne. Un nouveau plan d'aménagement pour la gestion durable des peuplements de chêne-liège est nécessaire. Cet objectif est réalisable seulement si l'on dispose des modèles de croissance permettant de prévoir les conséquences de différents traitements sylvicoles. On a développé, sur la base des données d'analyses de tige, deux modèles pour estimer la croissance en hauteur et en diamètre des chênes-lièges dominants dans deux des régions les plus productives d'Espagne. Les équations en différences des modèles de Lundqvist-korf, Mcdill-Amateis et Richards ont été testées et ajustées en utilisant la méthode des moindres carrés généralisée. Les paramètres des équations ont été exprimés en fonction de caractéristiques des peuplements pour améliorer les modèles. La fonction de McDill-Amateis a été retenue comme modèle de la croissance en hauteur tandis qu'on a choisi l'équation de Richards avec $n$ dans l'exposant comme paramètre libre pour modèle de la croissance en diamètre. Ces deux modèles améliorent nos connaissances de la croissance du chêne-liège et doivent nous permettre d' améliorer la gestion des peuplements.

modèles de croissance / Quercus suber / site index / arbres dominants / durabilité

\section{INTRODUCTION}

Sustainable forest management has become a highly relevant topic both in forest and environmental policy since the United Nations Conference on Environment and Development (UNCED), held in Rio de Janeiro in June 1992. Sustainable forest management seeks to ensure that the behaviour of managed forest ecosystems is environmentally and socio-economically acceptable [16]. Sustainability must be defined with respect to three aspects: natural, social and economical sustainability [36] in correspondence with the diversification of forests functions. Forests are a key resource serving a multitude of functions. Forest resource managers are challenged with the task of balancing multiple and often conflicting interests while at the same time meeting economic requirements. This objective is especially difficult to achieve in the Mediterranean forests.

Mediterranean forests are characterized by a limited capacity to respond to systematic changes, enduring intense human influences, a great climatic, geomorphological, edaphic and biological variety and a difficult socio-economic environment [28]. Due to this heterogeneity, the management of the Mediterranean forests poses a complex problem. This complexity is especially relevant in cork oak stands because of its silvicultural specificities. The most important silvicultural feature of this species is that the main product is cork, which is removed periodically without felling the trees. Cork oak stands urgently require a plan for sustainable management in order to find solutions to the main silvicultural problems that currently exist:

\footnotetext{
* Corresponding author: msanchez@inia.es
} 
scarce natural regeneration, ageing of cork oak stands, loss of cork quality [41], intense pruning [8] and increased cork oak decline ("seca") [27].

Cork oak stands in Spain can be differentiated into open cork oak woodlands (low tree density, "dehesas") and cork oak forests (higher tree density) [27, 33] according to ecological, silvicultural and productive characteristics. Although the main production in open cork oak woodlands is cork extraction, they also provide grazing for domestic and wild livestock. These two productions are regulated by reducing the number of trees per hectare. Open cork oak woodlands are located in the west and southwest of Spain; they have an open structure with 10-60\% canopy cover and a well developed understory of annual grasses. They occupy 275000 ha (58\% of the total surface of Spanish cork oak stands) and produce 48000 t of cork, which corresponds to $54 \%$ of the Spanish cork production [27, 41]. Cork oak forests are mainly found in Catalonia and the south of Andalusia. These forests have a higher density and a substantial understory of shrubs such as Arbutus unedo, Juniperus sp., Ulex sp., Cistus sp., aromatic essences, etc. These forests cover 200000 ha ( $42 \%$ of the total surface) and produce $41000 \mathrm{t}$ of cork (46\% of the total production) [27, 41].

According to Dewar [16], models can contribute directly to the assessment of sustainable forest management by providing both qualitative understanding and quantitative predictions of the impact of various management practices on forest ecosystem behaviour over different timescales. Modelling research on cork oak has been focused primarily on cork production and quality. In Spain and Portugal, several models have been developed to estimate cork production [19, 26, 32, 39,43]. As regards wood growth, research has been scarce, and mainly focused on the effect of different factors such as debarking on cork oak growth $[10,14]$. The only cork oak growth model available at this time is the SUBER model [38,40], a management oriented growth and yield model, developed in Portugal for open cork oak woodlands. However, there is no growth model available for cork oak forests.

The first step towards elaborating a complete growth model for cork oak is the development of relations for potential growth. For modelling purposes, potential growth is usually defined as the maximum growth in a certain environment as represented by the dominant trees [22]. Height growth of dominant trees is used mainly to define the site index in even-aged stands and is one of the basic equations or submodels in growth and yield models [7, 31]. Another important submodel is the diameter increment equation which can be formulated using a "potential growth $\times$ modifier" approach. In this approach, a function is selected which defines the potential diameter growth of competition-free trees, and then a competitive adjustment factor (the modifier) is introduced to take the effects of competition into account [23]. The height growth models for dominant cork oak trees allow us to estimate the site quality of stands and the minimum time that a regeneration block must be closed off to livestock in order to avoid damage during the regeneration phase. On the other hand, diameter growth models for dominant trees, allow us to estimate the minimum time required for a cork oak, (for a given site quality), to reach the minimum diameter to be debarked.
Table I. Description of the cork oak stands under study.

\begin{tabular}{lcc}
\hline & Catalonia & $\begin{array}{c}\text { Natural Park } \\
\text { of "Los Alcornocales" }\end{array}$ \\
\hline Latitude (N) & $42^{\circ} 48^{\prime}$ & $36^{\circ} 47^{\prime}$ \\
Longitude (W) & $2^{\circ} 49^{\prime}$ & $5^{\circ} 45^{\prime}$ \\
Annual mean precipitation (mm) & 700 & 1000 \\
Annual mean temperature $\left({ }^{\circ} \mathrm{C}\right)$ & 15 & 17 \\
Mean temperature of the warmest & $26($ July) & 34 (July) \\
month $\left({ }^{\circ} \mathrm{C}\right)$ & & \\
Soil (FAO) & Dystric & Calcic \\
& Cambrisols & Cambrisols \\
N (stems/ha) & 260 & 220 \\
BA (m ${ }^{2}$ ha $\left.{ }^{-1}\right)$ & 13 & 14 \\
\hline
\end{tabular}

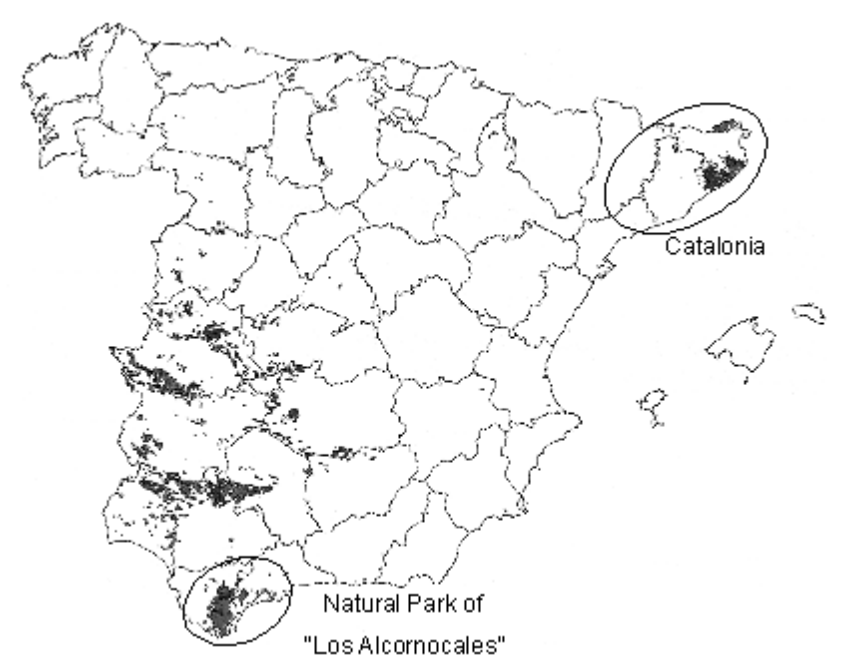

Figure 1. Distribution of Quercus suber L. in Spain and localization of the two studied regions.

The aim of this study is to develop height and diameter growth models for dominant cork oaks and to define a site index for Spanish cork oak forests. The regions selected to carry out this research are two of the main cork producing areas in Spain and are representative of the Spanish cork oak forests.

\section{MATERIALS AND METHODS}

\subsection{Data}

Stem analysis data were obtained from two different cork oak areas in Spain (Fig. 1): the Natural Park of "Los Alcornocales" in the South and Catalonia in the North-East. The characteristics of both areas are summarized in Table I.

In each of these areas, sample trees deemed to be dominant, healthy and rot free, were selected in even-aged stands in different site conditions. Trees were felled as close to the ground as possible. Sectioning was carried out cutting disks at the base of the tree, at a height of $50 \mathrm{~cm}$, at breast height $(1.30 \mathrm{~m})$, and at $50 \mathrm{~cm}$ intervals along the stem. Rings 
Table II. Mean, standard deviation and range of the main characteristics of the sample trees subjected to stem analysis in the two studied areas (CAT and PNLA).

\begin{tabular}{|c|c|c|c|c|c|c|}
\hline Area & $n$ & Variable & Minimum & Maximum & Mean & Standard deviation \\
\hline \multirow[t]{7}{*}{ CAT } & 40 & $d$ & 11.1 & 41.4 & 25.0 & 8.6 \\
\hline & & $h$ & 4.7 & 11 & 8.0 & 1.5 \\
\hline & & $h f$ & 1.6 & 3.6 & 2.5 & 0.5 \\
\hline & & hd & 1.3 & 2.1 & 1.7 & 0.2 \\
\hline & & Crown & 1.8 & 7.9 & 4.9 & 1.7 \\
\hline & & Age & 30 & 158 & 80.3 & 38.5 \\
\hline & & $h / d$ & 21.4 & 54.3 & 34.7 & 9.3 \\
\hline \multirow[t]{7}{*}{ PNLA } & 45 & $d$ & 10.8 & 52.5 & 26.7 & 13.5 \\
\hline & & $h$ & 4.3 & 15.9 & 8.3 & 2.9 \\
\hline & & $h f$ & 1.5 & 5.7 & 3.0 & 1.0 \\
\hline & & hd & 1.1 & 3.5 & 2.0 & 0.6 \\
\hline & & Crown & 1.6 & 13.6 & 4.7 & 2.7 \\
\hline & & Age & 34 & 128 & 65.2 & 31.4 \\
\hline & & $h / d$ & 19.8 & 61.3 & 34.3 & 9.2 \\
\hline
\end{tabular}

CAT: Catalonia; PNLA: Natural Park of "Los Alcornocales"; $n$ : number of sample trees, $d$ : diameter at breast height $(\mathrm{cm}) ; h$ : tree height (m); $h f:$ bole height (m); $h d$ : debarking height (m); Crown: crown diameter (m); Age: number of rings at stump height (years); $h / d$ : height to diameter ratio (cm/cm).

were counted on each disk. Tree age was obtained as the number of rings on the base disks and age at each height level was calculated as the difference between tree age and the number of rings at that level. Ring width for each breast height section was measured in a direction corresponding to the mean radius section with a linear positioning digitiser tablet (LINTAB), and the data obtained were saved and processed with the aid of TSAP software [42].

Carmean's correction to the height [11] was not applied because the possible error can be considered imperceptible due to the slow height growth in cork oaks.

The following variables were measured for each sample tree in both areas: diameter at breast height $(\mathrm{cm})$, crown projection diameter $(\mathrm{m})$ measured in two perpendicular directions, bole and tree heights (m) measured with a tape-measure on the felled tree and debarking height (m). The characteristics of the sample of trees in each region are given in Table II.

\subsection{Growth modelling}

For model fitting, the "Difference Equation" method was chosen because it is base age invariant $[12,17]$ and allows the use of any temporal series of data, whatever the length, such as those resulting from stem analysis. Furthermore, this method affords other advantages like the possibility of using data from trees which are younger than the base age [24]. The "Difference Equation" method allows the calculation of height or diameter at any age, from the data values observed at any other given age:

$$
f\left(y_{2}\right)=f\left(y_{1}, t_{1}, t_{2}\right)+\varepsilon
$$

where $y_{2}$ is the value of the dependent variable (height or diameter) at age $t_{2} ; y_{1}$ is the corresponding value at age $t_{1} ; \varepsilon$ is the additive error.

\subsubsection{Candidate functions}

The candidate growth equations considered for representing height and diameter growth were these of Richards (1), Lundqvist-Korf (2) and McDill-Amateis (3):

$$
\begin{gathered}
y=A\left(1-e^{-k t}\right)^{\frac{1}{1-n}} \\
y=A\left(e^{t}\right)^{\frac{k}{n}} \\
y_{2}=\frac{A}{1-\left(1-\frac{A}{y_{1}}\right)\left(\frac{t_{1}}{t_{2}}\right)^{n}}
\end{gathered}
$$

where $y_{i}$ is the value of the tree variable at age $t_{i} ; A$ is the asymptote and $n, k$ are parameters.

In order to obtain difference forms of the Lundqvist-Korf and Richards equations, one of the parameters may be left free leaving two parameters to be statistically estimated. The difference forms of the Richards and Lundqvist-Korf growth equations were taken from Amaro et al. [2]. The McDill-Amateis equation is based on dimensional analysis methodology and has no integral form $[3,25]$. The functions will henceforth be referred to as: RCp, which is the Richards function where $\mathrm{p}$ is the free parameter ( $k$ or $n$ ) of the difference form, LKp is the Lundqvist-Korf function where $\mathrm{p}$ is the free parameter $(k$ or $n)$ of the difference form and MA is the McDill-Amateis equation.

These functions were selected because they are widely used in forest research. Moreover, the difference equations for these functions are reciprocal, which means that when fitting the model, the two variableage pairs $\left(y_{1}, t_{1}\right)$ and $\left(y_{2}, t_{2}\right)$ can be switched without affecting the height or diameter growth predictions, or the properties of the model itself [24]. 


\subsubsection{Data structure}

The stem analysis produced one height-age pair $\left(h_{\mathrm{i}}, t_{\mathrm{i}}\right)$ for each stem disk. In the case of the diameter growth model, the number of diameterage pairs $\left(d_{\mathrm{i}}, t_{i}\right)$ obtained for each breast height disk was equal to the number of growth rings counted at that level. The data used for fitting the difference equations were structured in such a way as to include all possible growth intervals. Then for a given tree, all possible pairs of age-dependent variables $\left(t_{\mathrm{i}}, y_{\mathrm{i}}\right)$ were considered. According to Goelz and Burk [20] and Huang [24] this data structure provides the most stable and consistent results. In the case of the diameter, due to the large number of diameter-age pairs obtained, it was decide to reduce the number of pairs to improve SAS software performance and avoid problems caused by the high correlation between intra-tree observations. This reduction was made by selecting the diameter-age pairs at 5 year age intervals. In this study, the total number of pairs of observations which resulted from using all the possible growth intervals were 4740 for the height growth model and 16350 for the diameter growth model.

\subsubsection{Model selection}

The selection process for the growth models involved: (a) fitting the candidate growth equations; (b) parameter redefinition; (c) characterisation of the model error.

\section{(a) Model fitting}

Fitting of the candidate growth equations was done using the generalized nonlinear least squares (GNLS) method. The autocorrelation correction proposed by Goelz and Burk [20] was used to describe the error term of the model in order to address the correlations from stem analysis data. As we used all possible growth intervals, the error term $e_{i j}$ was expanded following an autoregressive process:

$$
y_{i i}=f\left(x_{i}, y_{j}, x_{j}, \beta\right)+e_{i j} \quad \text { with: } e_{i j}=\rho \varepsilon_{i-1, j}+\gamma \varepsilon_{i, j-1}+\varepsilon_{i j}
$$

where $y_{i j}$ represents the prediction of height or diameter at age $i$ by using $y_{j}$ (height or diameter) at age $j ; x_{i}, x_{j}$ (age $i \neq j$ ) are predictor variables; $\rho$ represents the autocorrelation between the current residual and the residual obtained by estimating $y_{i-1}$ using $y_{j}$ as a predictor variable; and $\gamma$ represents the relationship between the current residual and the residual obtained by estimating $y_{i}$ using $y_{j-1}$ as a predictor variable. The generalized nonlinear least squares estimate of the parameter matrix $\beta$ in equation (4) was obtained using the PROC MODEL procedure of the SAS/ETS software [34].

The functions were chosen according to the following considerations: goodness-of-fit, predictive ability, biological sense and compliance with the assumptions of homoscedasticity, lack of autocorrelation and normality of residuals.

The goodness-of-fit of the functions was analysed through the sumof -squares error (SSE) and the modelling efficiency coefficient (EF), which compares the observed and estimated values in a similar way to $R^{2}$ does in linear regression.

The predictive ability of the functions was evaluated using prediction errors or PRESS residuals. These residuals were calculated by omitting each observation in turn from the data, fitting the model to the remaining observations, predicting the response for the omitted observation and comparing the prediction with the observed value: $y_{i}-\hat{y}_{i,-i}=e_{i,-i}(i=1,2, \ldots, n)$ where is the observed value, $\hat{y}_{i,-i}$ is the estimated value for observation $i$ (where the latter is absent from the model fitting) and $\mathrm{n}$ is the number of observations. Each candidate equation has $n$ PRESS residuals associated with it and the PRESS (Prediction Sum of Squares) statistic is defined as [30]:

$$
\text { PRESS }=\sum_{i=1}^{n} y_{i}-\left(\hat{y}_{i,-i}\right)^{2}=\sum_{i=1}^{n}\left(e_{i,-i}\right)^{2} .
$$

The bias and precision of the estimations obtained with the different functions were analysed by computing the mean of the PRESS residuals (bias) and the mean of the absolute values of the PRESS residuals (precision). Descriptive statistics of location for the residuals were also calculated $\left(\mathrm{P}_{99}, \mathrm{P}_{95}, \mathrm{P}_{5}\right.$ and $\left.\mathrm{P}_{1}\right)$ where $\mathrm{P}_{k}$ is the $k$ th percentile.

The biological sense of each fitted function was evaluated through its asymptotic value $(A)$, which had to be realistic.

The multicolinearity was assessed in terms of the condition number of the correlation matrix for the partial derivates with respect to each one of the parameters. The condition number is defined as the largest condition index, which is the square root of the ratio of the largest eigenvalue to each individual eigenvalue. When the value of the condition number exceeded 30 , the effect of the multicolinearity was considered serious and the model was discarded [4].

The heteroscedasticity associated with the error terms of the models was analysed by plotting the variance of the residuals against the observed values. If an heteroscedasticity of the residuals was detected, it was corrected by using a weighted generalized non linear least squares estimation.

(b) Parameter redefinition

Once the best growth equation was selected, the parameters of the retained function were redefined in the following way.

As stem analysis data came from two regions, in both growth models each parameter was expanded as:

$$
\theta_{j}=\alpha_{0}+\alpha_{r e g} \cdot \text { reg }
$$

where $\theta_{j}$ is the $j$ th parameter of the function and reg is a binary variable set to zero for the Natural Park of "Los Alcornocales" and to one for Catalonia. The use of this equation, for practical purposes, is equivalent to considering two unrelated equations for both regions, but with the same error structure [1].

In the diameter growth model for dominant trees, site index and height to diameter ratio were incorporated into the equations by defining the parameters of the growth function as:

$$
\phi_{j}=\alpha_{0}+\alpha_{s i} \cdot S I+\alpha_{h / d} \cdot h / d
$$

where $\phi_{j}$ is the jth parameter of the function; SI is the site index calculated using the height growth equation, and $h / d$, is the height to diameter ratio (where $h$ is tree height in metres and $\mathrm{d}$ is tree diameter in centimetres). Through this procedure, the parameters of the function were related to other tree and stand features, but the form of the original function remained the same [13, 23].

The site index was defined using the height growth model for dominant cork oaks. The height to diameter ratio was used to estimate the effect of stand density on diameter growth, as it provides a good indication of stand density during the life of the tree [9], and also because it seems to be significantly correlated to stand basal area [44].

(c) Characterisation of model error

The validation of the selected functions was done by characterisation of the model error, both for the height and diameter growth models of dominant cork oak trees [35, 37]. For this purpose, a self-sufficient resampling type validation method was used. Taking into account the sample size and the characteristics of the data, a leave-one-out method, also called "Jackknife", was used. Thus, the models were fitted $n$ times, leaving out each tree once, so that the number of fittings was equal to the number of trees.

Both the mean of the prediction residuals and the mean of the absolute prediction residuals were estimated using equation (8) and the bias and variance using equations (9) and (10) respectively [15]:

$$
\hat{e}(\cdot)=\frac{1}{n} \cdot \sum_{i=1}^{n} \hat{e}
$$


Table III. Estimated parameters of the fit and predictive ability statistics of the candidate functions for height and diameter growth models.

\begin{tabular}{|c|c|c|c|c|c|c|c|c|c|c|c|}
\hline Function & $\mathrm{EF}$ & SSE & $A$ & $n$ & $k$ & Mpress & MApress & $\mathrm{P}_{99}$ & $\mathrm{P}_{95}$ & $\mathrm{P}_{5}$ & $\mathrm{P}_{1}$ \\
\hline \multicolumn{12}{|c|}{ Height growth model } \\
\hline $\mathrm{LK} k$ & 0.855 & 3194.8 & 17.533 & 1.314 & & 0.191 & 0.708 & 3.208 & 1.850 & -1.183 & -2.135 \\
\hline MA & 0.894 & 2332.2 & 19.550 & 1.467 & & 0.009 & 0.600 & 2.557 & 1.420 & -1.273 & -2.881 \\
\hline $\mathrm{RC} k$ & 0.893 & 2366.2 & 17.024 & 0.323 & & -0.009 & 0.609 & 2.571 & 1.416 & -1.307 & -3.115 \\
\hline \multicolumn{12}{|c|}{ Diameter growth model } \\
\hline $\mathrm{LK} k$ & 0.95 & 81796.6 & 52.11 & 1.33 & & 2.25 & 5.32 & 11.60 & 8.17 & -10.84 & -18.98 \\
\hline $\mathrm{RC} k$ & 0.99 & 21217.0 & 67.19 & -0.03 & & -0.02 & 1.79 & 8.67 & 4.31 & -4.19 & -7.61 \\
\hline $\mathrm{RC} n$ & 0.99 & 16167.6 & 176.39 & & 0.002 & -0.06 & 1.56 & 7.17 & 3.27 & -3.79 & -6.53 \\
\hline
\end{tabular}

EF: modelling efficiency; SSE: sum of squared errors; $A, n, k$ : parameters; Mpress: mean of the PRESS residuals; MApress: mean of absolute values of the PRESS residuals; $\mathrm{P}_{k}$ : $k$ th percentile of the residuals distribution.

$$
\begin{gathered}
b_{j a c k}=-\frac{1}{n} \cdot \sum_{i=1}^{n}\left((n-1) \cdot\left(\hat{e}_{(\cdot)}-\hat{e}\right)\right) \\
u_{j a c k}=-\frac{1}{n \cdot(n-1)} \cdot\left(\sum_{i=1}^{n}\left((n-1) \cdot\left(\hat{e}_{(\cdot)}-\hat{e}\right)\right)^{2}-n \cdot b_{j a c k}^{2}\right)
\end{gathered}
$$

where $n$ is the number of trees in the sample; $\hat{e}_{(\cdot)}$ is the mean of the prediction residuals $(\hat{e})$ or the mean of the absolute prediction residuals when tree $i$ is not included in the fitting.

\section{RESULTS}

\subsection{Height growth model}

\subsubsection{Model selection}

The results obtained by fitting the candidate equations are shown in Table III. All parameters for all the candidate functions were significant at an $\alpha$ level of 5\% except for the Lundqvist-Korf ( $\mathrm{LKa}$ ) and Richards ( $\mathrm{RCa}$ and $\mathrm{RCn}$ ) difference equations that leave $\mathrm{A}$ or $\mathrm{n}$ as free parameters.

The Lundqvist-Korf (LKk) and Richards (RCk) equations present a low asymptote value ( $A$ parameter) according to the empirical knowledge on cork oak [33]. Based on the results shown in Table III, the difference form of the McDill-Amateis equation (MA) was selected because the fit was better and gave a consistent asymptote.

To determine the nature of the heterocedasticity in the MA equation a graphical analysis of the mean squared residuals in $50 \mathrm{~cm}$ height intervals was made [6]. As shown in Figure 2, the variance of the error tends to decrease as tree size increases, except for the last height interval that coincides with a small number of observations, so it was assumed that for height values over $7 \mathrm{~m}$ the variance remains constant. The following function gave the best fit for the means of squared residuals grouped in height classes:

$$
\operatorname{Var}\left(\varepsilon_{i}\right)=0.6892\left[\min \left(h_{1}, 7\right)^{-0.6486}\right]
$$

where $\operatorname{Var}\left(\varepsilon_{i}\right)$ is the variance of the residual error, $h_{1}$ is height (m) at age $t_{1}$ and $\min \left(h_{1}, 7\right)$ is a function that returns $h_{1}$ when

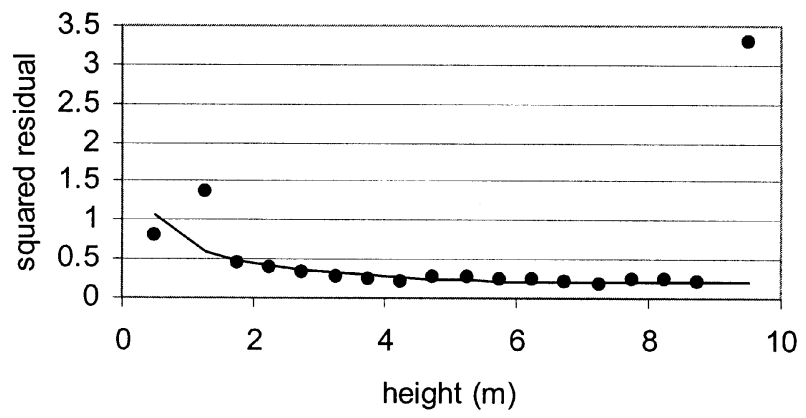

Figure 2. Mean squared residuals by tree height classes for the McDill-Amateis (MA) height growth function. The solid line indicates estimated variance function.

height is smaller than $7 \mathrm{~m}$ and returns 7 when height is larger than $7 \mathrm{~m}$. A weighted generalized non linear least squares fitting was then undertaken using $1 / \operatorname{Var}\left(\varepsilon_{i}\right)$ as the weighting factor.

\subsubsection{Parameter redefinition}

In order to determine the possible differences between the two regions studied, the MA equation was fitted with a weighted generalized non linear least square technique including regionalized parameters (see Eq. 6). All parameters in the equation were significant at an $\alpha$ level of $5 \%$.

In Figure 3, the height growth model obtained with and without regional differentiation, are represented graphically after forcing the curves to pass through the age-height points $(80,6)$, $(80,8),(80,10),(80,12)$ and $(80,14)$. This graphical comparison between regional growth curves indicates that there is a high level of similarity between dominant height growth patterns, except for the highest site index class in Catalonia, possibly because of the small number of trees sampled in this quality class.

The analysis of the variability of the modelling efficiency against age and against prediction interval is shown in Figure 4. Results indicate that a single height growth model could be used for both regions. 


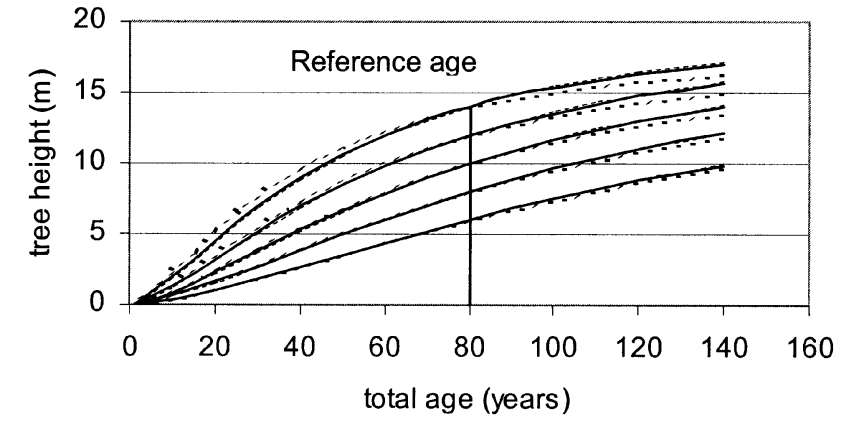

Figure 3. Height growth curves obtained using the McDill-Amateis (MA) function, both without differentiating the two regions (continuous line) and with differentiation: Catalonia (dashed line) and the Natural Park of "Los Alcornocales" (dotted line). (The height growth curves represented were selected so as to reach the height of $6,8,10$, 12 and $14 \mathrm{~m}$ high at the reference age of 80.)

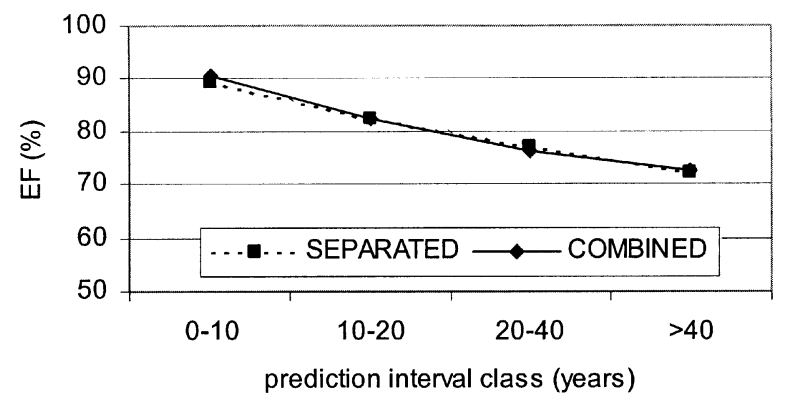

(a)

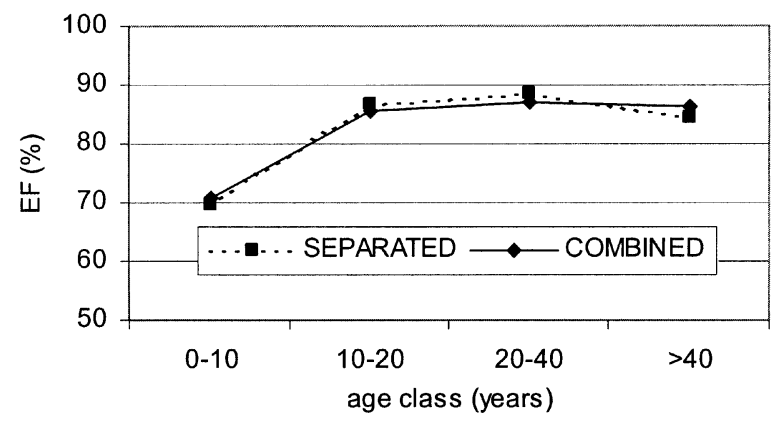

Figure 4. Analysis of modelling efficiency (EF) variability with prediction interval class (a) and age class (b).

Based on these results, the following difference form of the McDill-Amateis equation (MA) with same parameters was proposed as the height growth model for dominant cork oak trees in the Natural Park of "Los Alcornocales" and in Catalonia, equation (12):

$$
h_{2}=\frac{20.7216}{1-\left(1-\frac{20.7216}{h_{1}}\right)\left(\frac{t_{1}}{t_{2}}\right)^{1.4486}}
$$

where $h_{i}$ is the height (m) at age $t_{i}$ (years).

Site index was defined as the top height reached at 80 years old and then five quality classes were defined ranging from

(b)

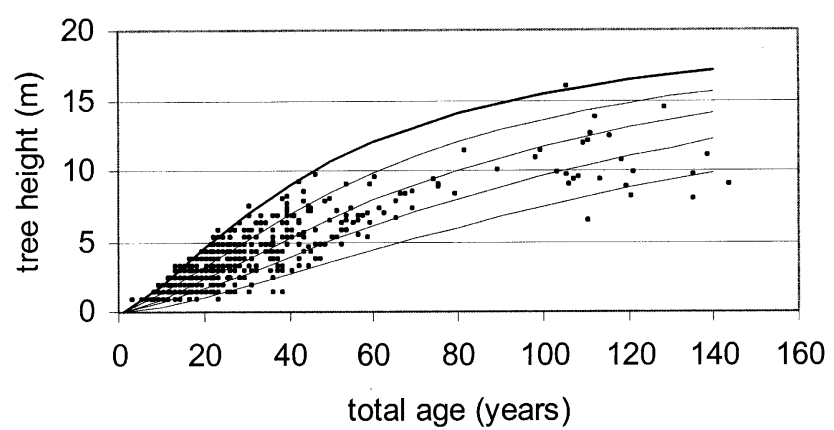

Figure 5. Height growth model for dominant cork oak trees in the Natural Park of "Los Alcornocales" and in Catalonia represented for the site quality classes defined (see text). The dots represent the height-age pairs from the sample.

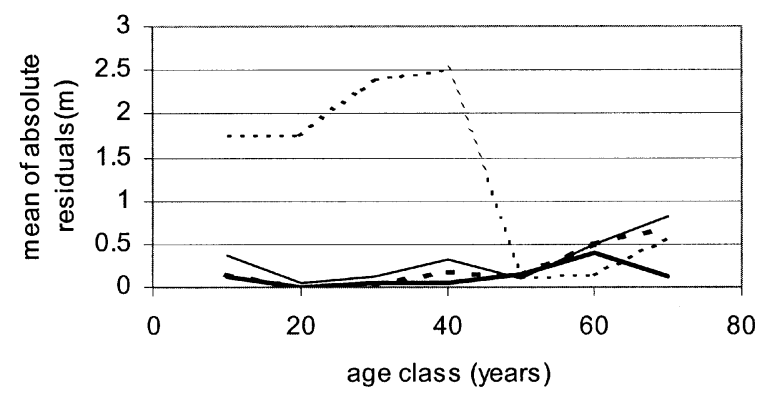

(a)

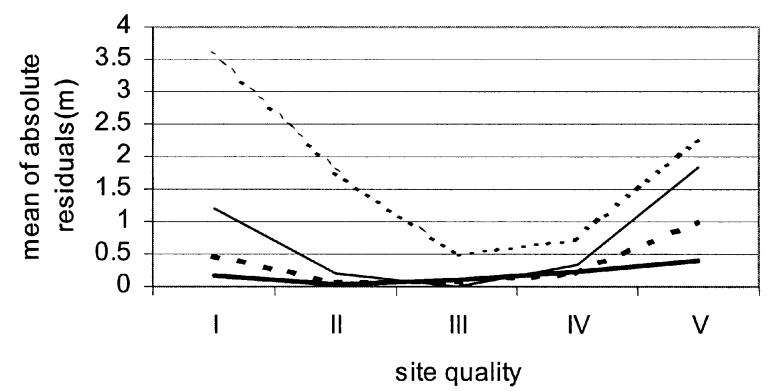

(b)

Figure 6. Mean of absolute prediction errors by age class (a) and by site quality class (b) for four time prediction intervals $\left(t_{2}-t_{1}\right)$.

$14 \mathrm{~m}$ for quality I to $6 \mathrm{~m}$ for quality $\mathrm{V}$, with a $2 \mathrm{~m}$ step between each quality class.

The height model defined by equation (12) is represented graphically in Figure 5 for each site quality class. The age-height pairs from the sample are also shown on the graph.

\subsubsection{Characterisation of model error}

The prediction error increased with age class (except for the prediction interval $\left.t_{2}-t_{1}>40\right)$ and with the prediction interval (Fig. 6a). The best results were obtained with predictive intervals of less than 40 years; beyond that age interval, the error 
Table IV. Bias $\left(b_{\text {jack }}\right)$ and variance $\left(v_{\text {jack }}\right)$ of the mean predicted residuals (Mrp) and of the mean absolute values of predicted residuals (MArp) calculated using the Jackknife regression method for height and diameter growth models.

\begin{tabular}{|c|c|c|c|c|}
\hline \multirow{2}{*}{ Model } & \multicolumn{2}{|c|}{$b_{\text {jack }}$} & \multicolumn{2}{|c|}{$v_{\text {jack }}$} \\
\hline & Mrp & MArp & Mrp & MArp \\
\hline Height & $2.4310^{-16}$ & $-2.7710^{-14}$ & 0.00042 & $1.7710^{-5}$ \\
\hline Diameter & $-1.5110^{-15}$ & 0 & $8.2110^{-6}$ & $3.8410^{-6}$ \\
\hline
\end{tabular}



Figure 7. Mean squared residuals by tree diameter classes for Richards ( $\mathrm{RCn}$ ) diameter growth function. The solid line indicates estimated variance function.

became much more important. In fact, for prediction intervals of ten years, the prediction error can be considered negligible.

Furthermore, the prediction error was the lowest for site qualities II and III, but also increased with the prediction interval (Fig. 6b).

The values for bias and variance obtained for the mean predicted residuals and for the mean absolute values of predicted residuals are shown in Table IV.

\subsection{Diameter growth model}

\subsubsection{Model selection}

Table III shows the results obtained by fitting the candidate equations. The difference form of the Richards equation that leaves $A$ as free parameter (RCa) did not converge. Furthermore, the difference form of the Lundqvist-Korf equation that leaves $A$ as free parameter (LKa) and McDill-Amateis (MA) equation were discarded because of the presence of multicolinearity (the condition number exceeded 30).

Based on the results shown in Table III, the difference form of the Richards equation that leaves $n$ as the free parameter $(\mathrm{RCn})$ was selected because the fit was better and gave a consistent asymptote $(A)$.

The mean squared residuals were plotted by tree diameter classes for the RCn equation (Fig. 7). The variance of the error tends to decrease as tree size increases, except for the two last diameter classes which are scarcely represented in the data set,

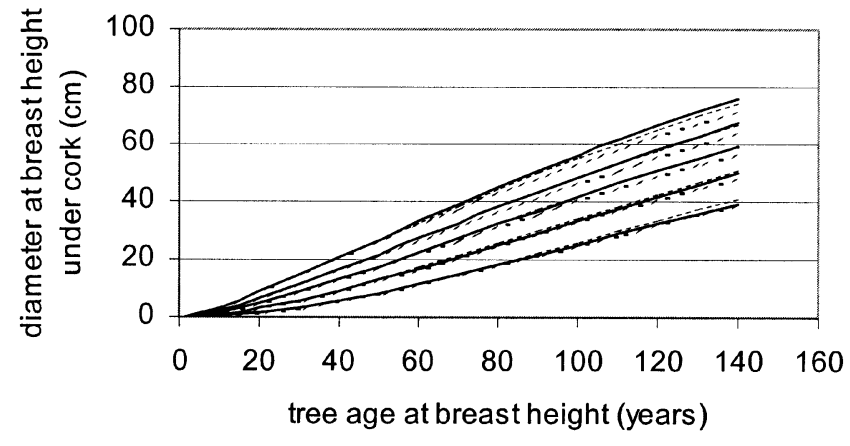

Figure 8. Diameter growth curves obtained using the Richards (RCn) function, both without differentiating the two regions (continuous line) and with differentiation: Catalonia (dashed line) and the Natural Park of "Los Alcornocales" (dotted line). (The diameter growth curves were represented in terms of each site quality class and mean values of height to diameter ratio for each site quality class.)

so it was assumed than for diameter values larger than $20 \mathrm{~cm}$ the variance of the error remains constant. A weighted generalized non linear least squares fitting was performed using $1 / \operatorname{Var}\left(\varepsilon_{i}\right)$ as the weighting factor, with:

$$
\begin{aligned}
\operatorname{Var}\left(\varepsilon_{i}\right)= & -0.0008\left[\min \left(d_{1}, 20\right)^{3}\right]+0.036\left[\left(\min \left(d_{1}, 20\right)^{2}\right]\right. \\
& -0.587\left[\min \left(d_{1}, 20\right)\right]+4.359
\end{aligned}
$$

where $\operatorname{Var}\left(\varepsilon_{i}\right)$ is the variance of the residual error, $d_{1}$ is diameter at age $t_{1}$ and $\min \left(d_{1}, 20\right)$ is a function that returns $d_{1}$ when diameter is smaller than $20 \mathrm{~cm}$ and 20 when diameter is larger than $20 \mathrm{~cm}$. This function gave the best fit for the means of squared residuals grouped in diameter classes.

\subsubsection{Parameter redefinition}

The diameter growth models obtained with and without regional differentiation in the fitting process, are represented graphically (Fig. 8) in terms of each site quality class and mean values of height to diameter ratio for each site quality class. The trends observed in this graphical comparison and in the analysis of the modelling efficiency are similar to those found with the height growth model. Based on these results, we decided to use a single diameter growth model for the two regions.

To evaluate the influence of site quality and height to diameter ratio on the diameter growth of dominant trees, the Richards equation ( $\mathrm{RCn}$ ) was fitted using a weighted generalized non linear least squares technique in which the site quality and height to diameter ratio effects were incorporated. In the case of the asymptote $(A)$, both site index and height to diameter ratio parameters ( $A_{S I}$ and $A_{h / d}$, respectively) were significant. For the $k$ parameter, none of the two parameters $\left(A_{S I}\right.$ and $\left.A_{h / d}\right)$ were significant, which indicates that $k$ is not influenced by site quality or height to diameter ratio. The fitted values obtained by the weighted generalized non linear least squares regression for the site quality and height to diameter ratio under dependent parameters are shown in Table V. 
Table V. Estimated values of the site index (SI) and height to diameter ratio $(h / d)$ dependent parameters in the diameter growth model selected (RCn).

\begin{tabular}{lccc}
\hline Parameter & $\alpha_{o}$ & $\alpha_{S I}$ & $\alpha_{h / d}$ \\
\hline$A$ & 83.19 & 5.28 & -1.53 \\
$k$ & 0.0063 & & \\
\hline
\end{tabular}

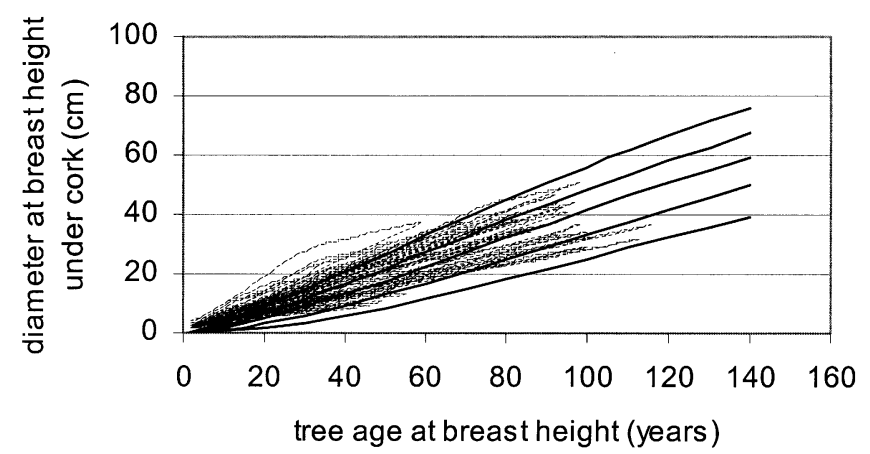

Figure 9. Diameter growth model for dominant cork oak trees in the Natural Park of "Los Alcornocales" and in Catalonia represented in terms of different site quality class and mean values of height to diameter ratio for each site quality class. The dotted lines represent the diameter growth curves of the sampled trees.

Then, the diameter growth model retained for dominant cork oak trees, both in the Natural Park of "Los Alcornocales" and in Catalonia, is the following:

$$
\begin{gathered}
d_{2}=(83.20+5.28 S I-1.53 h / d) \frac{\ln \left(1-e^{-0.0063 t_{2}}\right)}{\ln \left(1-e^{-0.0063 t_{1}}\right)} \\
\frac{\ln \left(1-e^{-0.0063 t_{2}}\right)}{\times d_{1}}
\end{gathered}
$$

where $d_{i}$ is the diameter at breast height under cork $(\mathrm{cm})$ at age $t_{i}$ (years); $S I$ is the site index $(\mathrm{m}) ; h / d$ is height to diameter ratio $(\mathrm{cm} / \mathrm{cm})$.

The diameter growth model defined by equation (14) is represented graphically in Figure 9 in terms of the different site index classes and mean values of height to diameter ratio for each site index class. The figure also displays the diameter-age pairs from the sample disks.

\subsubsection{Characterisation of model error}

Figures 10a shows that the model selected returned the best results for age classes under 50 years and that error became greater when the prediction interval $t_{2}-t_{1}$ was larger than 40 years.

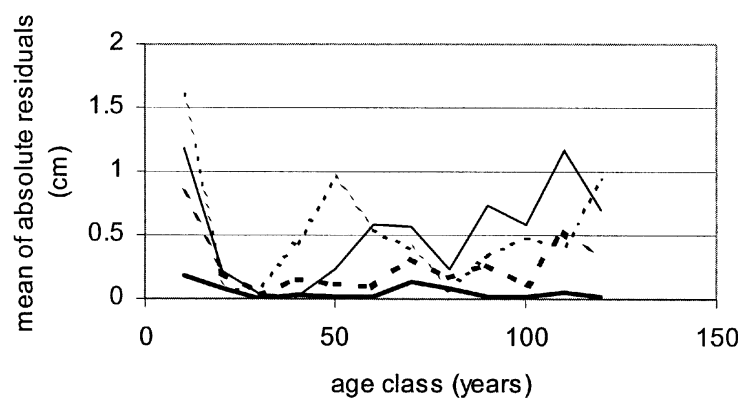

(a)

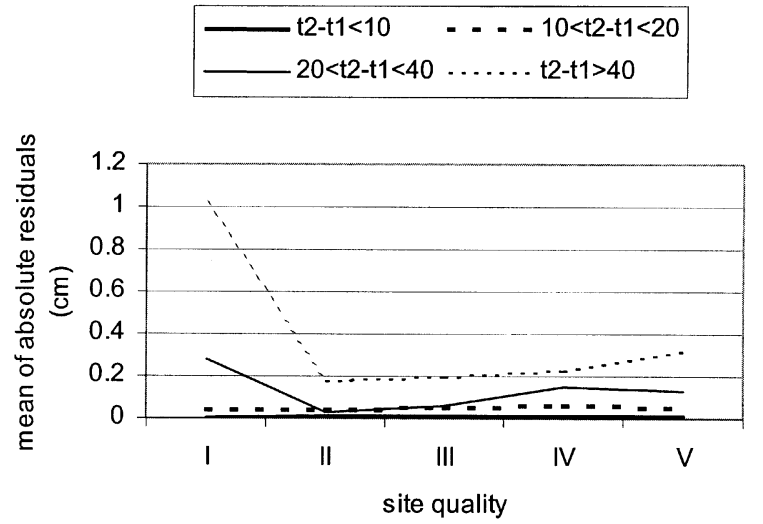

(b)

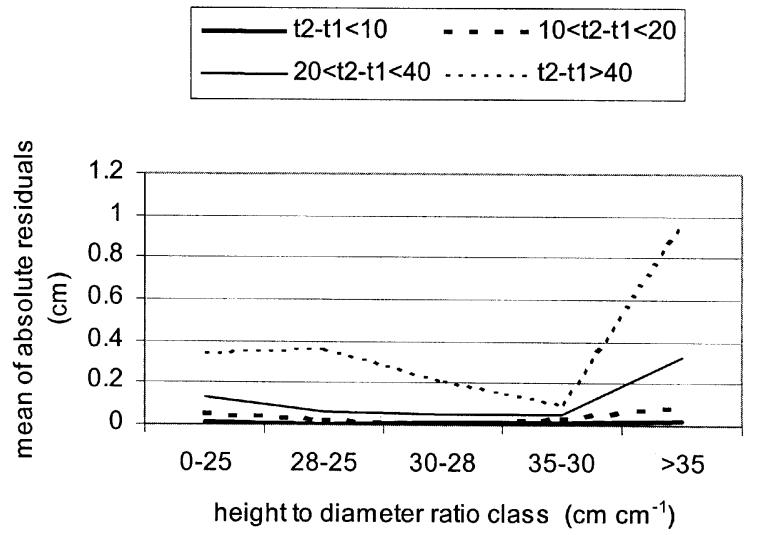

(c)

Figure 10. Mean of absolute prediction errors by age class (a), by site quality class (b), and by height to diameter ratio class (c) for four time prediction intervals $\left(t_{2}-t_{1}\right)$.

Figure 10b shows the mean absolute error values according to site quality for different values of $t_{2}-t_{1}$. The prediction error increases with the prediction interval, being greater for quality classes I and V, possibly due to fewer observations in these classes.

As shown in Figure 10c, the prediction error is minimal for height to diameter ratio values lower than 35 . As in the previous results the error increases when the prediction interval is larger than 40 years.

The values for bias and variance obtained for the mean predicted residuals and the mean absolute values of predicted residuals are shown in Table IV. 


\section{DISCUSSION}

In this study, height and diameter growth models were developed for dominant trees in cork oak forests. Both models contribute significantly to improving our knowledge of cork oak growth in Spain. Moreover, this is the first study of its kind conducted in this country. There are two main reasons for this delay in the development of cork oak growth models: firstly, the difficulty in determining the age of trees (in order to reconstruct growth curves) because increment cores tend to be illegible [21]; and secondly, the difficulty to obtain the permission to fell cork oaks, most of which, in Spain and Portugal, belong to privately owned stands.

In a previous study, Gourlay and Pereira [21] discussed the problems encountered when attempting to identify rings in cork oak wood. We believe that the difficulty was caused by the state of the tree sample (dead or dying trees, many of which may have included callused areas resulting from cork extraction). In our study, the disks samples used were all obtained from healthy trees, free from damage or infection, which greatly facilitated the identification of the wood rings.

The McDill-Amateis growth equation was selected for describing the height growth of dominant cork oaks in the two studied regions. The selection of this model was a compromise between biological and statistical constraints. The height growth model for dominant trees was used to define a site index for cork oak stands as the dominant height reached at the age of 80 years. In the first version of the SUBER model [38], the site quality measure used was the number of years required for a tree to reach a diameter at breast height outside cork of $16 \mathrm{~cm}$ (which is the size required for the first cork extraction, according to Portuguese legislation). The main reason for not using dominant height in the SUBER model was, among others, the difficulty in defining and measuring individual tree height due to the shape of cork oak trees (flat crown, lack of a main stem) and to formation and fructification prunings usually carried out on cork oaks. However, in our study, height was measured with a tape-measure on the sampled felled trees ensuring precise height measurements. In addition, it is undoubtedly better to base site index on dominant height rather than on diameter growth, which is also dependent on stand density and on the silvicultural treatments applied [13]. Since pruning are not carried out in cork oak forests, measuring cork oak heights in these stands is easier than in open woodlands where pruning is a habitual silviculture treatment. As a consequence, to determine site quality in cork oak forests using the height growth model developed in this study will be feasible without felling the trees. In future studies it would be interesting to investigate the environmental factors affecting cork oak site productivity and based on these factors, to model the cork oak site index.

In the latest version of the SUBER model, site quality was defined by the "growth intercept", that is the number of years necessary for dominant trees to reach a height of $1.30 \mathrm{~m}$ [40]. This site quality measure can be seriously affected by the environmental and cultural conditions prevailing during the first years of stand life. Then, the use of site index curves should give better results. Roughly, the site index classes defined in this study could correspond to "growth intercept" values ranging from 7 to 19 .
In a study concerned with the inter-regional variability of site index curves for Pinus pinea L. in Spain [5], an analysis of the modelling efficiency coefficient was used to determine whether differences exist between regional height growth models. The results obtained with this method in our study suggested that the use of a single height growth model for dominant cork oak trees, and of a single site index equation for cork oak forests, could be retained in Spain. The next step would be to develop a height growth model for open cork oak woodlands in Spain and Portugal, and to compare them in order to decide whether or not to use the same model for both countries, thus facilitating the comparison of cork oak stands.

The diameter growth model selection procedure indicated that the difference form of the Richards equation with $n$ in the equation as the free parameter resulted in the greatest precision and most consistent biological signification of the parameter estimates. Both site quality and height to diameter ratio had to be included as predictive variables. Parameter $k$, on which the shape of the curve depends [2], was not influenced by site quality or density. Therefore, the curves obtained for diameter growth of dominant cork oaks were anamorphic as were the curves developed by Tomé [38] for the SUBER model. On the other hand, the asymptote of the dominant diameter curves $(A)$ was influenced by site quality and height to diameter ratio. Thus, diameter increment increases as site quality increases and stand density (competition) decreases.

At 140 years old (considered as the upper limit for production of quality cork [27]), the diameter values obtained using our model are similar to those obtained by Tomé [38] with the SUBER model for open woodlands. In our model, the diameter values range from $85.7 \mathrm{~cm}$ for Quality I to $35.5 \mathrm{~cm}$ for Quality V, whilst in the SUBER model, the diameters varied from $70 \mathrm{~cm}$ for the best quality to $30 \mathrm{~cm}$ for the worst.

The analysis of the mean absolute error, for four time prediction intervals, was effected for both height and diameter growth models. The decreased precision when the prediction interval length increased was obvious for both models. The greatest error was obtained when the prediction interval exceeded 40 years and the smallest error when it was below 20 years. This highlights the difficulty to predict tree growth for long prediction intervals. However, both models seem to be very precise for a 10 year prediction interval, which is the usual timescale used in management plans.

The bias and variance values obtained when applying the Jackknife method were very low, both for the height and diameter growth models, which indicates the validity and goodnessof-fit of both models. When the size of the sample does not allow the data to be split into two parts, one for the estimation and one for the validation of the model, the same data must be used for both these procedures [15]. This situation leads to an error rate known as the 'apparent rate', which is lower than the real one (negative bias). However, using the Jackknife method, a less biased error rate can be obtained [18].

These growth models for dominant trees are very useful in the management of cork oak forests. For a given site index, the potential height growth curves allow us to estimate the minimum time that a regeneration block must be closed off to livestock. This period during which the regeneration block is fenced off, has a great economic and silvicultural importance. 
If this period of protection is not long enough, there is a risk that wild or domestic animals will seriously damage or destroy the young trees during the regeneration process by breaking stems. Those damaged trees, if they survive, will have short or crooked stems, which will affect the production of quality cork in the future. According to Montero and Cañellas [27, 29] this period of protection must last until the young trees reach a height of $2 \mathrm{~m}$. Using the height growth model developed, the number of years required for a cork oak to reach a height of $2 \mathrm{~m}$ can be estimated to 10 and 30 years for the best and worst qualities respectively.

Diameter growth curves for dominant trees allow us to estimate the minimum time required for a tree, on a given site quality, to reach a diameter of $20 \mathrm{~cm}$ at breast height, at which point cork may be extracted for the first time. This information is necessary to calculate the time required from the start of regeneration in a block to the beginning of cork production in the same block. Spanish legislation sets at $60 \mathrm{~cm}$ over virgin cork, the circumference at breast height that trees must reach before being stripped for the first time. By using the diameter growth equation established and assuming a virgin cork radial width of $2.7 \mathrm{~cm}$, the age at which cork oak trees can be debarked for the first time varies from 20 years for Quality I to 77 years old for Quality V.

Cork oak forests are of great importance, not only in terms of the economic value of the cork, but also because of the important ecological and social roles which these forests play in the Mediterranean region. Therefore, these stands require a management plan that ensures sustainability. This objective is only possible through the use of growth models which allow us to forecast the consequences of different silvicultural treatments in the future of the stands.

In this study, both height and diameter growth models have been developed for dominant trees in cork oak forests. These models help us to improve our knowledge of the species and as a consequence, enhance the management planning in these stands.

Acknowledgements: The authors wish to thank R. Calama, M del Río and I. Cañellas for reviewing the manuscript and for their helpful comments. We also want to thank Adam Collins for checking the English version. The research was partially supported by a grant to the corresponding author from the Forest Research Centre CIFOR-INIA.

\section{REFERENCES}

[1] Amaro A., Reed D., Themido I., Tomé M., Stand growth modelling for first rotation Eucalyptus globulus Labill. in Portugal, in: Amaro A., Tomé M. (Eds.), Empirical and process based models for forest tree and stand growth simulation, 1997, pp. 99-110.

[2] Amaro A., Reed D., Tomé M., Themido I., Modelling dominant height growth: Eucalyptus plantations in Portugal, For. Sci. 44 (1998) 37-46.

[3] Amateis R.L., McDill M.E., Developing growth and yield models using dimensional analysis, For. Sci. 35 (1989) 329-337.

[4] Belsley D.A., Kuh E., Welsch R.E., Regression Diagnostics, New York, John Wiley \& Sons, Inc., 1980.

[5] Calama R., Cañadas N., Montero G., Inter-regional variability in site index models for even-aged stands of stone pine (Pinus pinea L.) in Spain, Ann. For. Sci. 60 (2003) 259-269.
[6] Calama R., Montero G., Interregional nonlinear height-diameter model with random coefficients for stone pine in Spain, Can. J. For. Res. 34 (2004) 150-163.

[7] Cañadas N., Pinus pinea L. en el Sistema Central (Valles del Tietar y del Alberche): desarrollo de un modelo de crecimiento y producción de piña, Ph.D. thesis, E.T.S.I. de Montes, Universidad Politécnica de Madrid, 2000, $356 \mathrm{p}$.

[8] Cañellas I., Montero G., The influence of cork oak pruning on the yield and growth of cork, Ann. For. Sci. 59 (2002) 753-760.

[9] Cardillo Amo E., Caracterización productiva de los alcornocales y el corcho en Extremadura, World Cork Congress, Lisboa, 2000.

[10] Caritat A., Molinas M., Vilar L., Masson P., Efecto de los tratamientos silvopastorales en el crecimiento del alcornoque, Scientia gerundesis 24 (1999) 27-35.

[11] Carmean W.H., Site index curves for upland oaks in the central states, For. Sci. 18 (1972) 109-120.

[12] Cieszewski C.J., Bella I.E., Polymorphic height and site index curves for lodgepole pine in Alberta, Can. J. For. Res. 19 (1989) 11511160.

[13] Clutter J.L., Fortson J.C., Peinar L.V., Brister G.H., Bailey R.L., Timber Management - A Quantitative Approach, John Wiley \& Sons, New York, 1983, 333 p.

[14] Costa A., Pereira H., Oliveira A., Variability of radial growth in cork oak mature trees under cork production, For. Ecol. Manage. 175 (2003) 239-246.

[15] Davidson A.C., Hincley D.V., Bootstrap methods and their application, Cambridge series in statistical and probabilistic mathematics, Cambridge University Press, 1997, 582 p.

[16] Dewar R.C., The sustainable management of temperate plantation forests: from mechanistic models to decision-support tools, EFI proceedings No. 41, 2001.

[17] Eflving B., Kiviste A., Construction of site index curves for Pinus sylvestris L. using permanent plot data in Sweden, For. Ecol. Manage. 98 (1997) 125-134.

[18] Efron B., Tibshirani R.J., An introduction to the bootstrap, Chapman and Hall, 1993.

[19] Ferreira M.C., Oliveira A.M.C., Modelling cork oak production in Portugal, Agrofor. Syst. 16 (1991) 1-54.

[20] Goelz J.C.G., Burk T.E., Development of a well-behaved site-index equation: jack pine in north central Ontario, Can. J. For. Res. 25 (1992) $137-156$.

[21] Gourlay I.D., Pereira H., The effect of bark stripping on wood production in cork-oak (Quercus suber L.) and problems of growth ring definition, in: Pereira H. (Ed.), Proceedings of the European Conference on Cork Oak and Cork, Centro de Estudos Florestais, Lisboa, 1998, pp. 99-107.

[22] Hahn J.T., Leary R.A., Potential diameter growth functions, in: A generalized forest growth projection system applied to the Lake States region, Gen, Tech. Rep. NC-49, USDA Forest Service, North Central Forest Experiment Station, 1979, pp. 22-26.

[23] Huang S., Titus S.J., An individual tree diameter increment model for white spruce in Alberta, Can. J. For. Res. 25 (1995) 1455-1465.

[24] Huang S., Development of compatible height and site index models for young and mature stands within an ecosystem-based management framework, in: Amaro A., Tomé M. (Eds.), Empirical and process based models for forest tree and stand growth simulation, 1997, pp. 61-98.

[25] McDill M.E., Amateis R.L., Measuring forest sites quality using the parameters of a dimensionally compatible height growth function, For. Sci. 38 (1992) 409-429.

[26] Montero G., Modelos para cuantificar la producción de corcho en alcornocales (Quercus suber L.) en función de la calidad de estación y los tratamientos selvícolas, Ph.D. thesis, INIA, Madrid, 1987, 277 p. 
[27] Montero G., Cañellas I., Manual de forestación del alcornoque (Quercus suber L.), MAPA-INIA, 1999.

[28] Montero G., Cañellas I., Sustainable management of Mediterranean forests in Spain, Unasylva 197 (1999).

[29] Montero G., Cañellas I., Selvicultura de los alcornocales en España, Silva Lusitana 11 (2003) 1-19.

[30] Myers R., Classical and modern regression with applications. Duxbury -Press, Boston, Massachusetts, 1986, 359 p.

[31] Nigh G., A comparison of fitting techniques for ponderosa pine height-age in British Colombia, Ann. For. Sci. 61 (2004) 609-615.

[32] Ribeiro F., Tomé M., Cork weight prediction at tree level, For. Ecol. Manage. 171 (2002) 231-241.

[33] San Miguel A., Allué M., Cañellas I., Montero G., Bengoa J., Torres E., The most important forest ecosystems and their silvopastoral treatments in Spain, IUFRO Centennial, Berlin-Eberswalde, Germany, 1992, $11 \mathrm{p}$.

[34] SAS/ETS User's Guide, version 8, Cary, NC: SAS Institute Inc., 1999.

[35] Soares P., Tomé M., Skovsgaard J.P., Vanclay J.K., Evaluating a forest growth model for forest management using continuous forest inventory data, For. Ecol. Manage. 71 (1995) 251-265.

[36] Sverdrup H., Holmqvist J., Svensson M., Wallman P., Thelin G., Defining the concept of sustainability and a demonstration of practical application of sustainable forest management based on the SUFOR experience, Proceedings of the IUFRO Conference on Decision support for multiple purpose forestry, Vienna, 2003.
[37] Tomé M., Soares P., A comparative evaluation of three growth models for eucalypt plantation management in coastal Portugal, in: Amaro A., Tomé M. (Eds.), Empirical and process based models for forest tree and stand growth simulation, 1997, pp. 517-533.

[38] Tomé M., Coelho M.B., Pereira H., A management oriented growth and yield model for cork oak stands in Portugal, in: Amaro A., Tomé M. (Eds.), Empirical and process based models for forest tree and stand growth simulation, 1997, pp. 271-289.

[39] Tomé M., Coelho M.B., Lopes F., Pereira H., Modelo de produção para o montado de sobro em Portugal, in: Pereira H. (Ed.), Proceedings of the European Conference on Cork Oak and Cork, Centro de Estudos Florestais, Lisboa, 1998, pp. 22-46.

[40] Tomé M., Coelho M.B., Almeida A., Lopes, F., O modelo SUBER. Estrutura e equações utilizadas, Relatórios técnico-científicos do GIMREF n $n^{\circ}$ 2/2001, Centro de Estudos Florestais, Instituto Superior de Agronomia, Lisboa, 2001.

[41] Torres E., Montero G., Los alcornocales del Macizo del Aljibe y sierras del Campo de Gibraltar, MAPA, 2000.

[42] TSAP-Time Series Analysis and Presentation, Version 3.0. Reference Manual, Frank Rin, Heidelberg, Germany, 1996.

[43] Vazquez F.J., Modelos preditivos de produção de cortiça e detecção precoce da qualidade, Ph.D. thesis, ISA, Lisboa, 2002, 358 p.

[44] Wang G.G., Is height of dominant trees at a reference diameter an adequate measure of site quality? For. Ecol. Manage. 112 (1998) $49-54$. 